\title{
Collaborations between universities and the business environment in Romania
}

\author{
Dan Miricescu ${ }^{1 *}$, Martin Heinisch ${ }^{2}$, and Laura Heinisch ${ }^{3}$ \\ "'Lucian Blaga" University of Sibiu, Industrial Engineering and Management Department, Romania, \\ Emil Cioran Street, No. 4, 550025 Sibiu, Romania \\ ${ }^{2}$ MHI Ingenieurgesellschaft mbH, Schnaiter Str. 11-13, Remshalden, Germany \\ ${ }^{3} \mathrm{~B}+\mathrm{H}$ Solutions GmbH, Schnaiter Str. 11-13, Remshalden, Germany
}

\begin{abstract}
Building closer relationships between universities and companies can encourage exchange of information between the two institutions, to create long-term partnerships and opportunities and stimulates innovation, creativity and entrepreneurship. The main objective of this research is to identify the significant elements of the collaboration between the university environment and the business environment in Romania, by extracting current information about this collaboration and to try to realise a general framework related to this issue. The research is part of a future larger investigation conducted as an integral part of the Erasmus + project Personalized Engineering Education in South Africa - PEESA III. The study analyzed the perceptions of respondents from some companies operating on the Romanian market, regarding the company in which they are activating and its level of cooperation with the university environment.
\end{abstract}

\section{Collaborations between universities and the business environment}

Collaborations between business environment and universities help higher education institutions to develop curricula and teaching techniques that meet the needs of both students and society [1]. These collaborations represent a common benefit for both universities and companies. As a result of these partnerships, new technologies that can improve the quality of life can be developed, but also young people will chase different sets of values and skills, that will help them as future employees [2].

Building closer relationships between universities and companies can encourage exchange of information between the two institutions, to create long-term partnerships and opportunities and stimulates innovation, creativity and entrepreneurship [2,3].

There are many activities through which companies can start cooperating with universities. And of these actions the most important are: trainings and internships for students and graduates, financial support of university research centers and networking [4, 5]. In the research presented, only a few of them will be found, but we decided to present them briefly, because these are the most common ways of intersection between business and academia environment founded in the literature.

* Corresponding author: dan.miricescu@,ulbsibiu.ro 


\subsection{Internship and practice}

Internship is perhaps the most popular form of collaboration. In recent years there have been launched a lot of internship programs, being a way for companies to recruit their future employees. For students, the internship is a learning opportunity, a way to they can gain practical experience in the field of interest. After graduating from college, most young people are looking for a stable job, but most of the time they lack certain skills.

Through an internship, students can develop skills that can help them in a professional way. Investing in young people and giving them the opportunity to develop professionally, accumulating a solid knowledge base, the labor market will provide increased quality of services in the future.

The companies that hire students that are at an entry level career have many benefits. The company gains a valuable human resource, who already knows how to perform his tasks efficiently.

\subsection{Financial support for university research centers}

Another step that companies can take is to invest in a university research center. Due to this initiative the industry will have access to the latest technologies and discoveries in the field in which it operates, and the advantages of this action will have a significant impact on the company's image and profit in the future. Collaborations like this bring benefits to both parties, as universities enjoy financial support, companies have access to the first to the results obtained from those discoveries.

\subsection{Networking}

Networking is used by professionals to widen their circles of acquaintances, find out about job opportunities, and to increase their awareness of news and trends in their fields.

Employees can teach a range of courses to students, both academically and in the classroom learning sessions (workshops, specialization courses, etc.) and can interact in an informal way.

Have another type of resource, the knowledge, through teachers, researchers and all the people they work with. Combining those two entities, networking sessions will bring benefits to both parties, and the ideas that come out following these discussions can change in a favorable way the evolution of both parties.

For the academic environment, which is characterized by having a slower evolution and a more calculated risk assessment, sometimes it will be difficult to keep up with the business environment, where things are constantly changing.

\subsection{Dual study programs}

Professional experience is highly appreciated by companies and, therefore, the lack of such experience is a major obstacle for people who are looking for their first job.

The term "dual education" is widely used as a comprehensive term, referring to the fact that teaching and learning (vocational education and training) is characterized by "duality" from two points of view:

- the duality of learning spaces (schools / vocational educational providers and training companies), which share the responsibility of providing theoretical and practical training; - the duality of the parties involved (public and private parties), who share responsibility for vocational educational and training policies and practices. 
According to UNESCO [6], "the dual education system is called 'dual' because it combines apprenticeship in a company and vocational education in a vocational school in a single course." [6] Within the company, the apprentice benefits from practical training, which is completed by theoretical training at the vocational school.

\section{Elements regarding the research methodology}

The main objective of this research is to identify the significant elements of the collaboration between the university environment and the business environment by extracting current information about this collaboration and to try to realise a general framework related to this issue. The research is part of a future larger investigation conducted as an integral part of the Erasmus + project Personalized Engineering Education in South Africa - PEESA III. This study will be extended by administering this questionnaire to partners from Germany, Poland and South Africa [7].

A secondary objective is to contribute to the strengthening of the didactic and research activity within the Romanian universities and to increase their connection to the realities and tendencies of the socio-economic environment.

The main categories of information that were intended to be obtained through the questionnaire on collaboration between universities and companies (UBC) would be:

- Identifying the way in which the level of communication between universities and the entrepreneurial environment is appreciated;

- Identifying the agreements realised to encourage partnerships between universities and the private sector;

- Determining the capacity of communication with the entrepreneurial environment for making more relevant the education and research activity of higher education institutions;

- Assessment of the extent to which there are communication barriers between the academic and the entrepreneurial environment;

- Identifying the capacity of the university environment to become an engine of regional development through the specialized consultancy offered, through scientific research, innovation and by applying the results at the level of companies;

- Knowledge of the extent to which respondents appreciate the concordance between the skills and qualifications offered by the academic environment and the needs of the labour market;

- Identifying the perspectives of companies' collaboration with the academic environment and the forms of collaboration that will be developed in the future.

The study analyzed the perceptions of respondents from some companies operating on the Romanian market, regarding the company in which they are activating and its level of cooperation with the university environment. The administration and analysis of the questionnaires was carried out between April and June 2020, the sample of respondents being made up of 50 people from different companies in Romania. Within this research, the survey unit was constituted by the entry level, middle level or top level managers who answered the questionnaire, but in particular were targeted those persons who deal with collaborations with the university environment within the company. To conduct the research, this was developed in Google Forms, and was distributed online (the questionnaire included a number of 15 questions). Some of the questions of the questionnaire had as idea, the theme of a study conducted under the auspices of the European Commission [2, 8], at the level of European Union countries, including Romania [6], conducted in June 2018, these being adapted to project requirements and specificities identified in this project. In this idea in the analysis to be presented, we will refer to also to this study results, to point common or different elements identified by us in the area of a close type of questions $[3,7]$. 


\section{Analysis of the main results}

\subsection{The importance of geographical location}

Most of the times the companies decide build collaborations with universities located in the proximity of the geographical area where also the companies are locate.

\begin{tabular}{|lc|}
\hline Local universities & $66 \%$ \\
\hline Universities inside the country & $\mathbf{5 0 \%}$ \\
\hline & \\
\hline & \\
\hline
\end{tabular}

Fig. 1. Importance of geographical location.

This result shows us that geographical position matters a lot to companies in choosing a university partner (Fig. 1). While most Romanian businesses cooperate with universities in the region $(66 \%)$, the results also report a high percentage for universities national $(50 \%)$. But only $16 \%$ collaborate with universities abroad, this shows the interest of companies in using human resources within the country.

\subsection{Number of partner universities}

Over $80 \%$ of Romanian companies cooperate with less than 4 universities and this is due to the fact that these companies collaborate mostly with universities in the country and the number of universities at national level is relatively low, $16 \%$ have established relationships with 5-10 partners and a very low percentage of $4 \%$ cooperate with over 10 universities (Fig. 2).

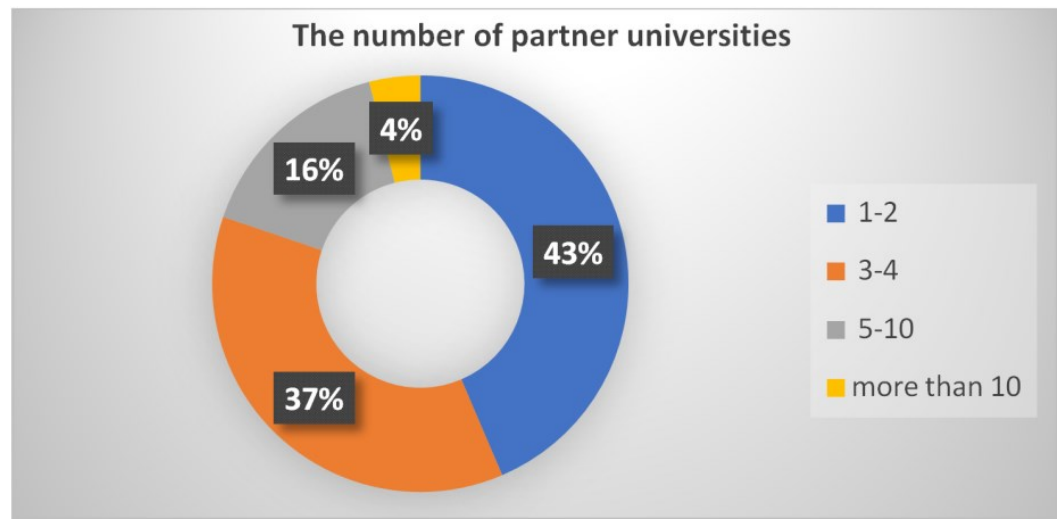

Fig. 2. Number of partner universities.

\subsection{Reasons why companies cooperate with universities}

Regarding the reasons why Romanian companies want to collaborate with universities and what are the activities they access most often, opinions are divided according to the needs of each company. 


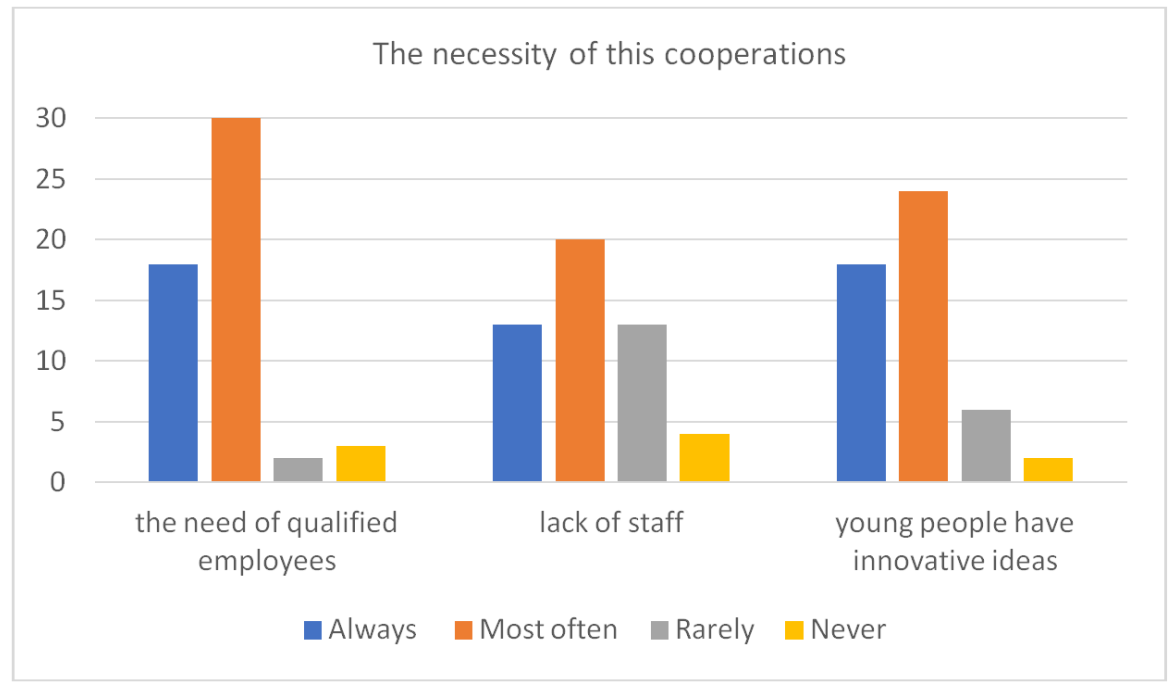

Fig. 3. Reasons why companies cooperate with universities.

From Figure 3 we can see that the lack of staff among Romanian companies qualified is a very big problem, and most of the time that is a reason for which companies decide to initiate partnerships with academia. Another important reason why these partnerships are beneficial is that young people have innovative ideas and can help companies to develop their products and services, by adapting them to market requirements.

\subsection{Activities carried out in collaboration with the university environment}

To the question 'Do you think that the collaborations with the university environment helped the company in its development?' A percentage of $90 \%$ answered in an affirmative way, this confirms the importance of these partnerships and the fact that they bring huge benefits to the business environment (Fig. 4).

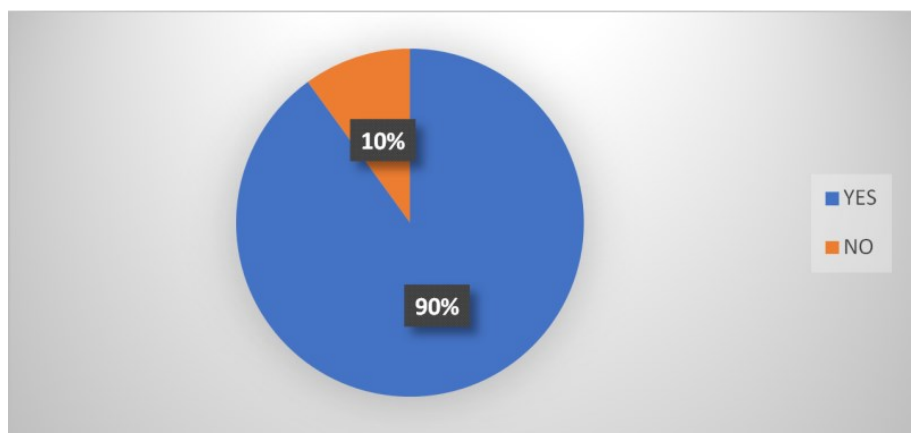

Fig. 4. Do you think that the collaborations with the university environment helped the company in its development?

And to find out why companies consider these partnerships important, we used an openended question to analyze each company's point of view. Although the way of expression was different, most respondents share the same idea, that young people are flexible and can be easily modeled according to the needs of the company. At the same time, a large part of the respondents consider that students bring added value within companies, even if at the 
beginning a process of training and integration of students within the company is needed, they adapt easily due to the fact that they are innovative and eager to learn new things.

\subsection{Factors influencing collaborations between universities and companies}

\subsubsection{Barriers in collaboration with the university environment}

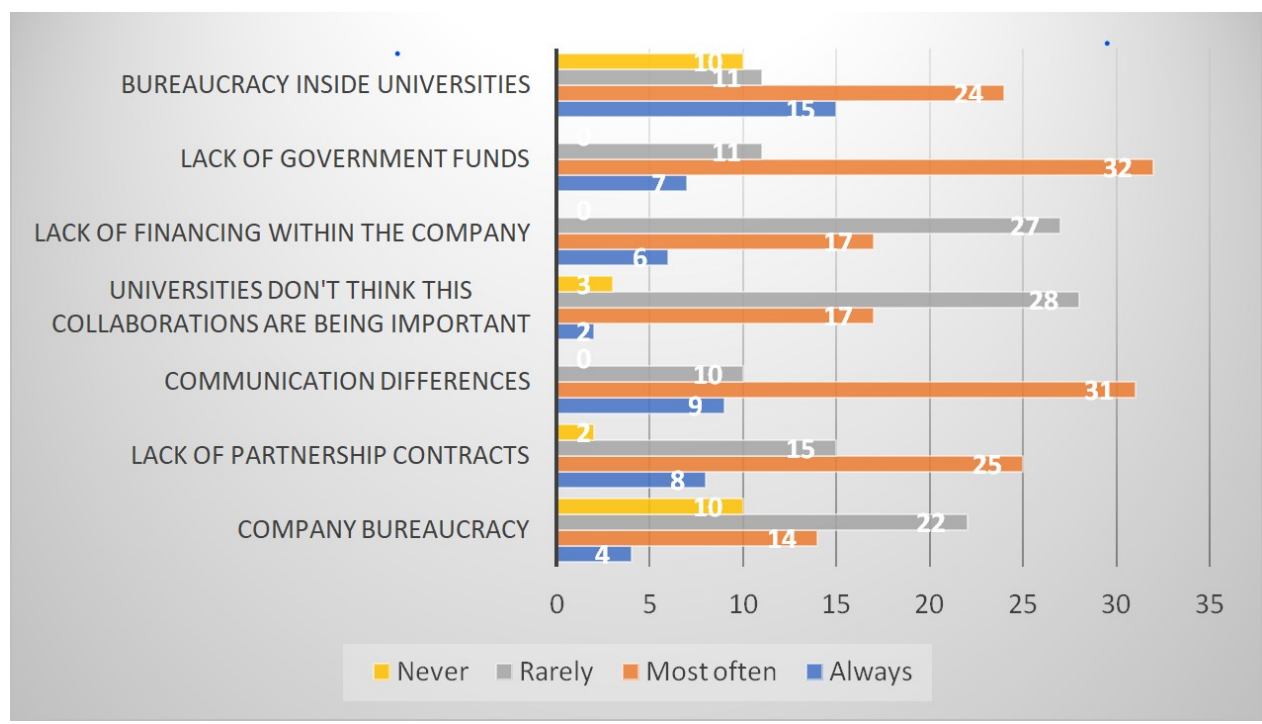

Fig. 5. The main factors that prevent a good development of these collaborations.

As can be seen from the Figure 5, the main factors that prevent a good development of these collaborations are: lack of government funds, differences in communication between academia and companies and bureaucracy within universities. On the other hand, companies say that the lack of funding at the company level and the bureaucracy within the company are often the barriers to partnerships with the university environment.

\subsubsection{Elements that facilitate collaborations between universities and companies}

The elements that facilitate these collaborations in Romania refer mostly to a relationship built between the two environments, to the presence of a previous connection based on mutual trust, but also in the interest of the university to benefit from the knowledge and services of the partner companies (Fig. 6).

\subsection{Activities to support collaborations between universities and companies}

Companies start a series of activities to support collaborations with the university environment. The main activities they initiate are (Fig. 7): constant meetings between business members and university environment, courses and practical activities for students and projects made by students in partnership with companies. 


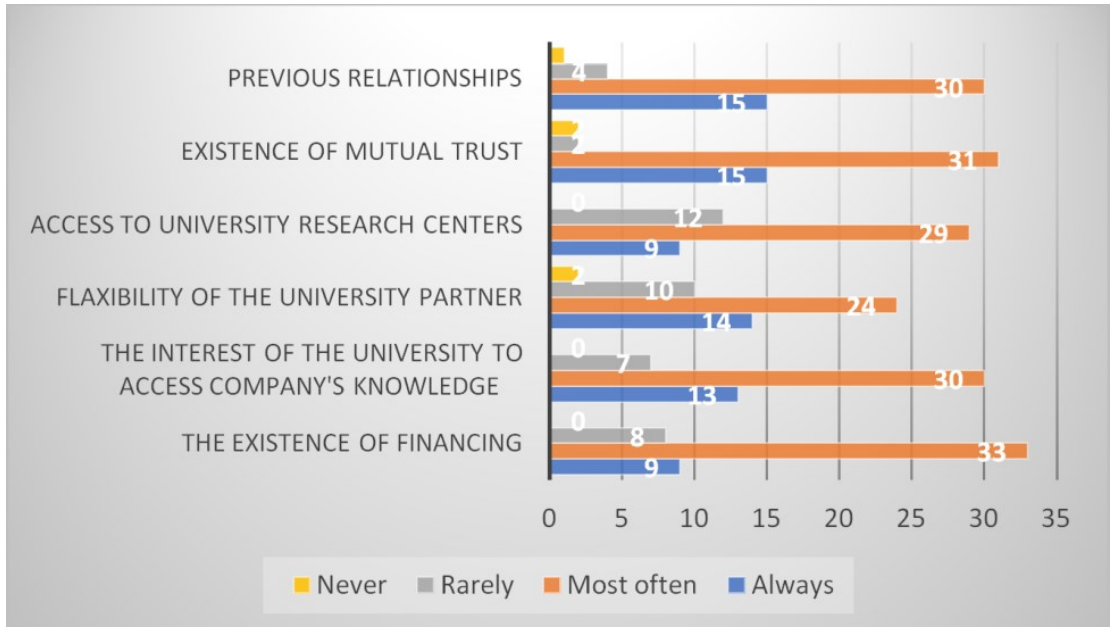

Fig. 6. The elements that facilitate these collaborations.

\subsection{The level of preparation of students}

On a scale of 1 to 5 ( 1 representing to a small extent, and 5 representing to a large extent) respondents had to express whether the level of preparation of students met the expectations of companies.

We found out that $50 \%$ of the respondents gave a grade of 3 , they consider that they are students have an average level of training, over $40 \%$ gave a grade of $4-5$, they said they were satisfied with level of education of students, and only $10 \%$ are considered relatively dissatisfied with the vocational training of young people.

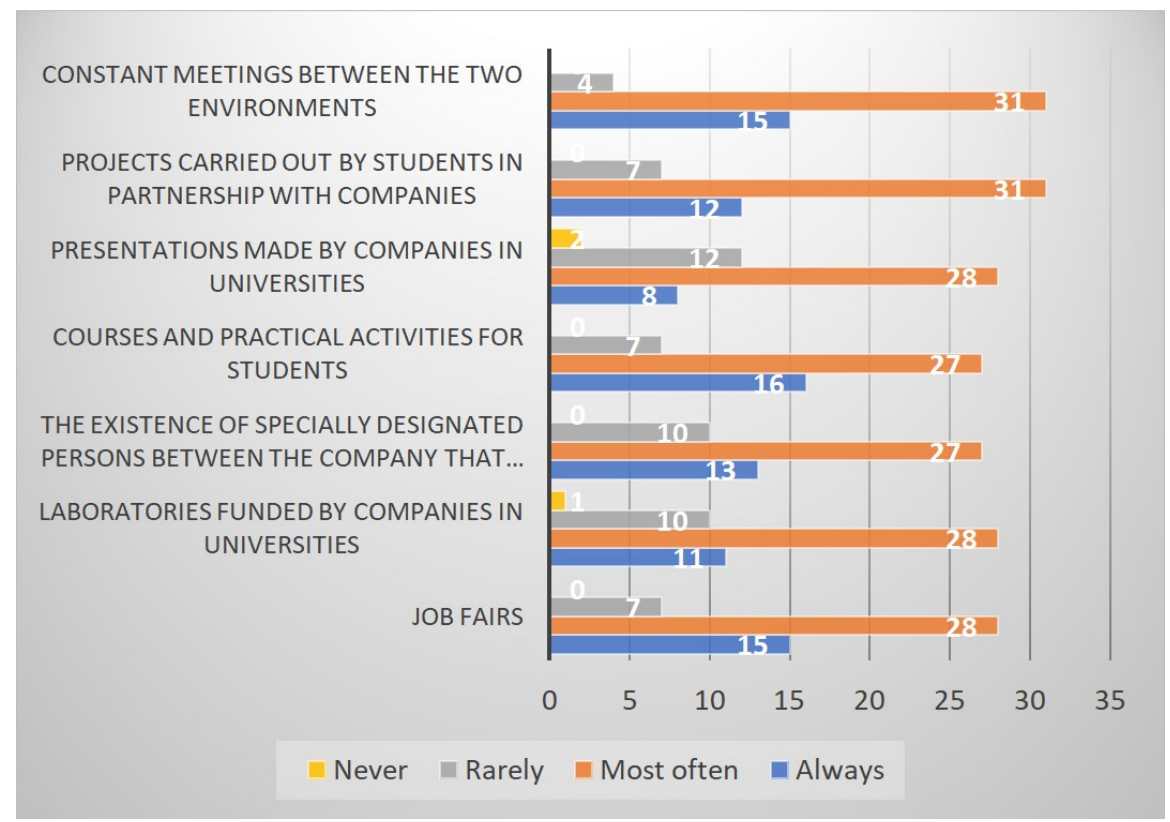

Fig. 7. Activities to support collaborations between universities and companies. 


\subsection{The experience in collaboration with the university environment}

On a scale of 1 to 5 ( 1 representing unsatisfactory and 5 representing satisfactory) respondents were asked to rate the experience they have had so far in their collaborations which they have achieved over time with Romanian universities. A percentage of $58 \%$ gave a grade of $4-5,40 \%$ a grade of 3 and a percentage of only $2 \%$ gave grades below average.

\subsection{Tips for strengthening these collaborations}

Respondents were asked to briefly state what they think universities should improve so that these collaborations take better shape and develop more on future. Most of the answers refer to the fact that universities should focus more much on the practical side to update the university curriculum more often, depending on market trends and to embrace an open mindset, aligned with current technology and standards.

However, many other answers refer to the fact that universities do not provide opportunities for collaboration to smaller companies, local companies, because they often focus their attention and all facilities for large firms such as Continental, Marquardt, etc... In this way there are many companies that find it difficult to reach students, especially those with a smaller budget, but who could provide jobs or internships for students, they consider that the degree of employability of students would be even higher than at present.

\subsection{Profile of respondents}

The position held within the company: The questionnaire was largely completed by general managers $(25 \%)$ and managers of the human resources department $(23 \%)$. The 'other' section (10\%) represents the functions of engineers and technicians (Fig. 8).

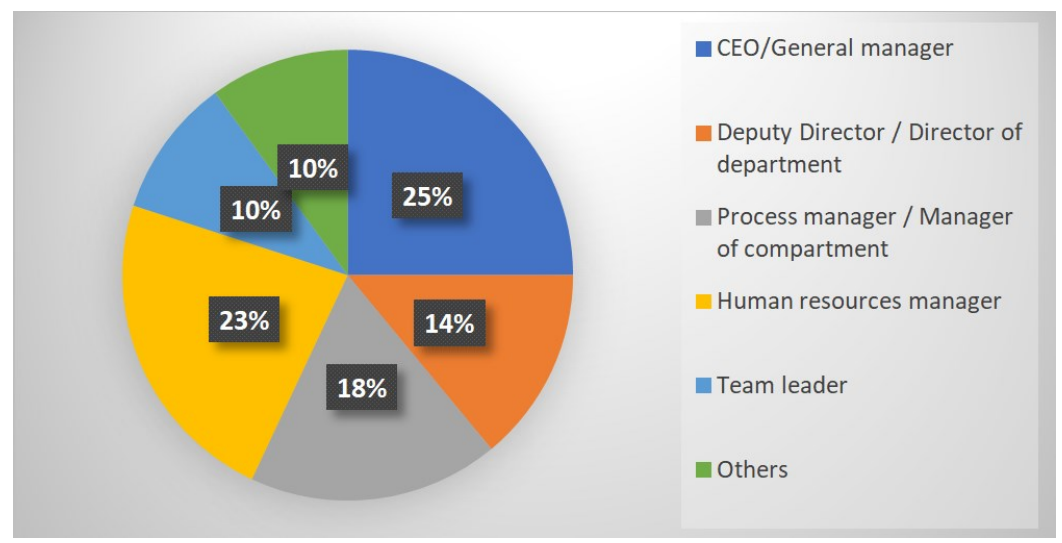

Fig. 8. The position held within the company.

Company type: Most companies in Romania are companies with private capital, hence the large number of respondents working for companies with private capital (94\%), while only $4 \%$ of respondents work for companies with majority state capital.

Number of employees: From the graph below (Fig. 9), it can be seen that $32 \%$ of respondents are employed in companies with a number very high number of employees (over 1000), 28\% are employed by companies with an average number of employees (between 249 and 1000) and 40\% of the respondents are employed in companies with a relatively small number of employees (under 249). 


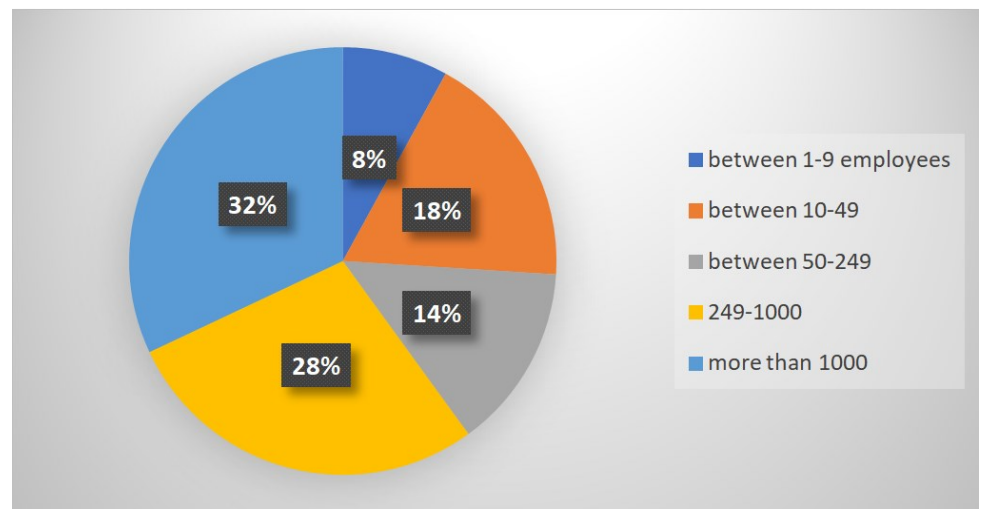

Fig. 9. Number of employees.

\section{Conclusions and recommendations}

After processing the data and interpreting the results, we came to a series of conclusions, which will be presented below:

- It is suggested as ways of communication between universities and the business environment to attend conferences, round tables, mutual consultation, and dialogues with graduates and constant meetings between members of the business environment and the university environment.

- One aspect highlighted by managers is the mismatch between competencies and qualifications offered by the academic environment and the needs of the labor market, this is certainly one of the aspects that most companies are dissatisfied with. Romanian universities need to update their curricula more often due to how quickly the world in which we live in changes their tendencies.

- Romanian businesses consider that the biggest impediment in these collaborations is bureaucracy within the faculty, followed by the statement that there are differences in communication between academia and business. Another very important barrier identified by respondents is the lack of government funds for collaboration with universities.

- As a result of collaborations with universities, companies consider that the biggest benefit is that it is the fact that young people have innovative ideas and thus find new solutions for their business, but also the fact that they need staff, and especially qualified staff.

- Regarding the factors that facilitate the cooperation, the companies consider that the most important factor is the access to the research / development facilities of the university but also the existence of previous relations between the business environment and the university. These results indicate the fact that to strengthen this relationship, both universities and companies must focus more on developing a close relationship for successful collaboration.

Based on the results of the study, the identification of the deficiencies of the communication and cooperation relationship between the academic and the entrepreneurial environment, we propose the following improvement measures:

- increasing the involvement of the local business environment in the development of internships for students and intensifying the request for advice from the academic environment;

- creating a favorable framework for the development of students entrepreneurial skills, thus so that undergraduate and dissertation work is based on the identification of solutions for the real problems of local companies; 
- cooperation between universities and the business environment must be intensified as part of universities education, research and innovation strategies;

- because the relationship with the private environment is, first and foremost, the responsibility of the academic environment, it must show a proactive and open attitude towards the private environment.

The management structures of the universities, but also the teachers must meet the companies, looking for partnerships and offering facilities and openness to the needs companies:

- Supporting smaller, local or entry level companies to initiating partnerships with the university environment;

- a more active involvement of student organizations in this collaboration process, to participate together with the management of the educational institution in the realization and implementation of the strategy relationship with the external environment.

- creating the conditions for stimulating the granting of private scholarships by enterprises such as source of performance of students and graduates of higher education institutions.

From what has been analyzed, the relationship between universities and companies tends to take shape very well in the future, companies are increasingly eager to work with students and collaborate with universities.

However, there are several issues that need to be worked on for this relationship to be a tight one. The Romanian business environment is willing to provide all the necessary tools for a beneficial and long-lasting relationship between the two, but has higher expectations from him university partner, expectations that are expected to be met in the near future.

The research is part of a future larger investigation conducted as an integral part of the Erasmus ${ }^{+}$ project Personalized Engineering Education project in South Africa - PEESA III. This study will be extended by administering this questionnaire to partners from Germany, Poland and South Africa.

\section{References}

1. A. U. Rufai, A. R. Bin Bakar, A. Mat Rashid, MJSS 6, 6 (2015)

2. T. Davey, A. Meerman, V. Galan Muros, B. Orazbayeva, T. Baaken, The State Of UniversityBusiness Cooperation In Europe (Publications Office of the EU, 2018)

3. M. Ranga, C. Hoareau, N. Durazzi, H. Etzkowitz, P. Marcucci, A. Usher, Study on UniversityBusiness Cooperation in the US - Final report EAC-2011-0469 (LSE, 2013)

4. R. Lukman, D. Krajnc, P. Glavic, J. of Cleaner Production 17, 1143-1153 (2009)

5. S. Mehling, N. Kolleck, Sustainability 11, 4982 (2019)

6. European Commission, Eurydice, National Reforms in Vocational Training and Adult Learning Romania, https://eacea.ec.europa.eu/national-policies/eurydice/content/national-reformsvocational-education-and-training-and-adult-learning-56_en (2021)

7. C. Kifor, D. Dumitraşcu, D. Miricescu, O. Precup, M. Popelca, Personalized Engineering Education project in South Africa - PEESA III Report 2020 (Sibiu, Romania, to be published)

8. M. Melonari, A. Fodor, M. Ranga, T. Davey, A. Meerman, B. Orazbayeva, V. Galán-Muros, The State of Romanian University-Business Cooperation Report (Business Perspective) - Technical Report (Publications Office of the EU, 2018) 